Please quote as: Zierau, N.; Flock, K.; Janson, A.; Söllner, M. \& Leimeister, J. M. (2021): The Influence of Al-Based Chatbots and Their Design on Users' Trust and Information Sharing in Online Loan Applications. In: Hawaii International Conference on System Sciences (HICSS). 


\section{The Influence of AI-Based Chatbots and Their Design on Users' Trust and Information Sharing in Online Loan Applications}

\author{
Naim Zierau \\ University of St.Gallen \\ naim.zierau@unisg.ch \\ Matthias Söllner \\ University of Kassel \\ soellner@uni-kassel.de
}

\author{
Korbinian Flock \\ University of St.Gallen \\ k.flock@web.de
}

Jan Marco Leimeister

University of St.Gallen \&

University of Kassel

janmarco.leimeister@unisg.ch

\author{
Andreas Janson \\ University of St.Gallen \\ andreas.janson@unisg.ch
}

\begin{abstract}
Based on recent advances in Artificial Intelligence (AI), chatbots are now increasingly offered as an alternative source of customer service. For their uptake user trust in critical. However, little is known about how these interfaces fundamentally influence trust perceptions. In particular, it's unclear what exactly causes perceptual differences - the change towards a conversational interface or the usage of anthropomorphic design elements. In this study, an online experiment with 160 participants was conducted to examine the differential effects of conversational interaction and anthropomorphism on trust in the interface or the provider within the context of online loan applications. The results show that both treatment conditions affect trust in the interface and the provider by increasing perceptions of social presence. Meanwhile, trust in the interface significantly effects the intention to share information, while trust in the provider has no effect on behavioral intention.
\end{abstract}

\section{Introduction}

Recent advances in the area of Natural Language Processing (NLP) and the increasing adoption of Artificially Intelligence (AI)-based chatbots gradually transforms the way how users interact with companies $[1,2]$. Within this context, a proliferating trend is the introduction of chatbots for a variety of service encounters in order to both drive service efficiency and service experience [3]. These agents assist customers by engaging with them via text-based communication as an initial touchpoint for simple customer inquiries [4], but are also increasingly integrated in complex service operations such as customer advisory [5]. Contrary to industry expectations, however, customers' adoption of chatbots have been relatively low [6]. Observers note that one reason might be that the development of chatbots was initially based more on technology push than on market pull. Consequently, user wishes and needs were not sufficiently addressed [7]. In particular, a lack of trust is often highlighted by industry accounts as consumers are often reported to be skeptical about the new technology [8]. In specific, the increasingly humanlike nature of chatbots may highlight the role of trust [4]. In sum, usage of chatbots for different customer service encounters is becoming gradually omnipresent, but convincing consumers to switch towards these new service channels still presents a challenge based on a lack of trust [9].

Today, still little is known about how these novel human-computer interfaces may fundamentally change users' experience of the service process (i.e., trust) and impact their perceptions of the service firm, as well as the downstream consequences for users [10]. Emerging research has mostly focused on the effect of specific design features on different user perceptions amongst others trust, mostly in regards to their capability to manifest social clues [11]. However, studies that report on perceptual differences in regards to trust, when using a chatbot compared to using a static interface are rare $[12,13]$. Thus, it's not clear what exactly drives potential perceptual differences - the change towards a conversational interaction logic or the increased usage of anthropomorphic design elements. However, knowledge of these processes would enable a more elaborate design of these agents for specific contexts.

In general, there is a need to better understand how AI-based chatbots leverage trust in different customer service environments [4]. In the context of online loan applications, trust engineering is particularly important as users need to disclose personal information based on which the awarding decision including the concrete interest rate is taken. In other contexts, researchers have investigated various chatbot characteristics that could enhance perceptions of trust such as avatars [14] or 
conversational style [15]. Still few studies have explored particular IT artifact designs that could strengthen trust within financial contexts that are particularly sensitive to (over-)trust [16]. Hence, this paper aims to address this gap, by answering the following research question:

RQ: How do AI-based chatbots influence user trust in online loan applications?

To answer our research question, we conducted a $2 \times 2$ between-subject online experiment to test whether different interaction types (conversational vs. nonconversational) and different levels of anthropomorphism (low vs. high anthropomorphism) affects user trust in online loan applications. Based on a vignette study, we asked 160 participants from Amazon Mechanical Turk to apply online for a loan and in the process to disclose sensitive information. We found that participants using a chatbot showed both higher level of trust in the technology and the provider based on higher perceptions of social presence. Those participants that experienced higher trust in the interface were more willing to disclose information. Trust in the provider on the other hand did not affect information sharing intention. Thus, we contribute to research both on trust in AI and service research by showing that conversational interfaces and anthropomorphism effect overall trust by increasing perceptions of social presence and in effect lead to increased behavioral commitment. Moreover, this study provides practical contributions by showing that service providers can easily implement chatbots for standardized customer-facing processes such as loan applications to improve user experience.

The remainder of this paper is structured as follows. First, we provide an overview of the theoretical background and our hypothesis development. Section 4 describes the experimental setup in detail, including the procedure, the treatments, and the measurements. Afterwards, we present and discuss the results of our experiment. Finally, we address our study limitations and provide future avenues for research.

\section{Theoretical Background}

In this section, we first describe existing research on chatbots in customer service and highlight the issue of trust in this regard. Second, relevant trust research is briefly introduced.

\subsection{AI-Based Chatbots for Customer Service}

Chatbots are AI-based computer programs that assist users via text-based communication [16, 17]. Service providers typically adopt these agents to address specific customer goals [18]. Thereby, based on the service context, user interactions with chatbots either take the form of one-off engagements (e.g., general inquiries of a prospective customer) or are integrated in a long-term engagement with an existing customer [3]. Gradually, these interfaces develop to become the dominant user service interface as they promise to both improve service efficiency and service experience [19]. Initial application areas have been standardized customer-facing processes such as loan applications that are often already often automized through self-service technologies [20]. On the one hand, they enable to significantly improve service efficiency through intelligent automation [21]. On the other hand, they promise to increase service quality by enabling personalization, around the clock availability and immediate response times, and thus improved service quality [22]. However, despite technological advances that pay into above-mentioned capabilities, the interaction of many users with these agents have yielded mixed results indicating high failure rates [23]. Especially, a lack of trust in chatbots is often cited as the reason why customers are cautious to adopt these agents. This is problematic since trust is also crucial in many transactional relationships, especially those dealing with risks [24].

From literature, we know that a lack of trust represents a main hindrance to the adoption of AI-based IS (e.g., [8]). The humanlike traits of chatbots, in particular their capability for natural language interaction [16] and the ability to reflect social cues, may even highlight the issue of trust [25]. Although IS research has investigated trust in various technologies for a long time [26], further research addressing trust in chatbots is needed [27]. This knowledge gap is critical, as from a sociotechnical perspective chatbots represent a novel form of IS that can be distinguished by its high degree of interaction and intelligence [28]. These capabilities may fundamentally affect how people develop trust in these systems and raise a number of theory and design-related questions, most prominently revolving around an emergent interaction paradigm (i.e., moving from designing graphical web interfaces to designing conversation with computer agents) [29]. Thus, substantial knowledge created in the area of trustbuilding mechanisms for e-consumer-environments cannot necessarily be adapted to the context of chatbots [30]. In specific, it is critical to better understand how these novel human-computer interface influence trust perceptions and associated behavioral consequences for the user [16].

\subsection{Trust in AI-Based Chatbots}

Traditionally, trust research has been focusing on studying relationships among human beings and organizations that are mediated by an IS such as for 
example the relationship of a customer to a service provider [31]. However, due to developments such as increasing automation, IS have itself become recipients of trust [32]. Automated systems such as AI-based chatbots in customer service are not only used to mediate trust relationships between human beings but to support their users in achieving specific goals, thereby exhibiting agency on their behalf [33]. Thus, it could be argued that these systems are increasingly becoming trustees in a trust relationship between the human user and a respective IS, according to the trust definition of [34]. Users, therefore, need to exhibit willingness to be vulnerable to the actions of an autonomous IS "based on the expectation that the other [i.e., a chatbot] will perform a particular action important to the trustor [i.e., a user], irrespective of the ability to monitor or control that other party [i.e., a chatbot]" ([34], p. 712). Besides the trust relationship between the user and the chatbot, multiple trust relationships and their interplay need to be considered. For instance, according to [31], trust is a complex phenomenon that needs to be decomposed into different trust-relationships focusing on the entities relevant to the context, such as for instance, trust in the provider of a service or trust in the specific interface (i.e., chatbot).

\section{Table 1. Review on Empirical Literature on Trust in Chatbots}

\begin{tabular}{|c|c|c|}
\hline Source & Study & Main Results \\
\hline [14] & $\begin{array}{l}\text { Interface } \\
\text { Anthropomorphism } \\
\text { - Avatar gender, } \\
\text { demeanor }\end{array}$ & $\begin{array}{l}\text { Male avatars and smiling } \\
\text { demeanors cause the } \\
\text { agent to be perceived as } \\
\text { more trustworthy. }\end{array}$ \\
\hline [35] & $\begin{array}{l}\text { Interface } \\
\text { Anthropomorphism } \\
\text { - Avatar gender }\end{array}$ & $\begin{array}{l}\text { Female agents are } \\
\text { perceived as more } \\
\text { competent and are hence } \\
\text { trusted more. }\end{array}$ \\
\hline [36] & $\begin{array}{l}\text { Interface } \\
\text { Anthropomorphism } \\
\text { - Avatar }\end{array}$ & $\begin{array}{l}\text { Avatars being perceived } \\
\text { as professional enhance } \\
\text { affect-based trust. }\end{array}$ \\
\hline [37] & $\begin{array}{l}\text { Interaction } \\
\text { Anthropomorphism } \\
-\quad \text { Conversational } \\
\text { Style }\end{array}$ & $\begin{array}{l}\text { Matching conversational } \\
\text { style between user and } \\
\text { agent increases trust in the } \\
\text { agent. }\end{array}$ \\
\hline [4] & $\begin{array}{l}\text { Interface } \\
\text { Anthropomorphism }\end{array}$ & $\begin{array}{l}\text { Anthropomorphistic } \\
\text { design cues increase trust } \\
\text { in interactive systems. }\end{array}$ \\
\hline$[38]$ & $\begin{array}{l}\text { Interaction } \\
\text { Anthropomorphism } \\
-\quad \text { Conversational } \\
\text { Style }\end{array}$ & $\begin{array}{l}\text { Agents adopting a } \\
\text { relational conversational } \\
\text { style are perceived as } \\
\text { being more trustworthy } \\
\text { than task-oriented agents. }\end{array}$ \\
\hline [39] & $\begin{array}{l}\text { Interaction Modality } \\
\text { - Talk vs. Chat } \\
\text { (Expression) }\end{array}$ & $\begin{array}{l}\text { Talking made users more } \\
\text { willing to share } \\
\text { information than texting. }\end{array}$ \\
\hline [40] & $\begin{array}{l}\text { Interaction Modality } \\
\text { - Talk vs. Chat } \\
\text { (Response, } \\
\text { Expression) }\end{array}$ & $\begin{array}{l}\text { Expression modality } \\
\text { predicted behavioral trust } \\
\text { (i.e., self-disclosure). } \\
\text { There was no effect of } \\
\text { response modality. }\end{array}$ \\
\hline
\end{tabular}

\begin{tabular}{|l|l|l|}
\hline [41] Interaction Modality & $\begin{array}{l}\text { Human voice-based } \\
\text { communication } \\
\text { (Response) }\end{array}$ & $\begin{array}{l}\text { significantly } \\
\text { influences users' } \\
\text { perceptions of social } \\
\text { presence, which in turn } \\
\text { enhances users' } \\
\text { trusting beliefs, }\end{array}$ \\
\hline
\end{tabular}

Chatbots can carry different social cues (i.e., design characteristics) that afford the user to build trust in the agent. Recently, as our literature review shows, researchers have started to explore the effects of some of these cues especially regarding the embodiment of the chatbot on user trust. For instance, initial research suggests that these cues (i.e., avatars, relational conversational style) may increase user trust through social presence (i.e., the feeling that another is psychologically present in interactions with information systems, e.g., [15, 42]). Accordingly, the design of chatbots might trigger users to exhibit emotional, cognitive, or behavioral reactions that are reminiscent of human interactions [43]. This suggests, that purposefully enhancing the human-likeness of chatbots may help to reduce user skepticism. Further, this research shows that these implicit associations between human-likeness and trust may be triggered when the reliability of new information systems is opaque - a core inference of AI-based systems. However, studies that report on perceptual differences in regards to user trust, when using a chatbot compared to using a static interface are rare [12]. Thus, it's not clear what exactly drives potential perceptual differences in regards to user trust - the change towards a conversational interaction logic or the increased usage of anthropomorphism - a gap we aim to address with this paper.

\section{Hypothesis Development}

To illustrate how AI-based chatbots will ultimately affect user trust and the intention to share information, we utilize the research model shown in Figure 1.

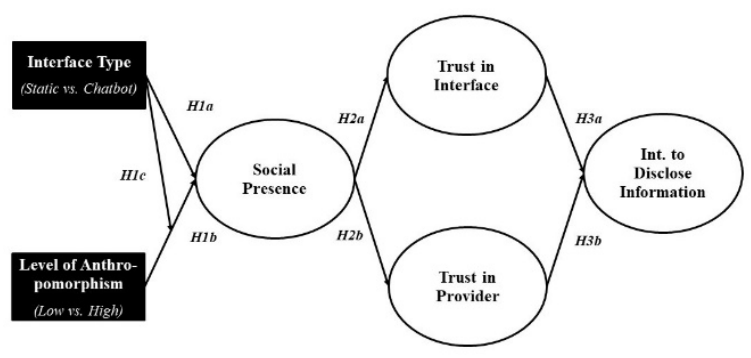

Figure 1. Research Model

According to social response theory, users tend to apply heuristics that they have learned from social 
situations with humans to interactions with computer agents under certain conditions [44]. It was shown that the interface of computer agents is able to transmit cues that subconsciously trigger social responses by users [43]. In this regard, one fundamental design choice relates to the use of conversational interfaces. Compared with non-conversational interfaces, chatbots can provide more sensory cues just by the dynamic way information is exchanged with the user. Moreover, a chatbot interface is able to engage users in interactions that feel more similar to regular face-to-face conversations, as they are provided with a natural way of exchanging information [11]. Therefore, it's not surprising that studies investigating the implementation of chatbots have found that those interfaces are perceived as more engaging und human-like, which in effect increased the feeling of social presence [45]. Thus, we hypothesize that we will see a similar effect in the case of loan applications:

Hypothesis 1a: Users of chatbot interfaces for loan applications will experience higher levels of social presence than users of static interfaces.

Human-likeness has been identified as an important antecedent of user acceptance across different disciplines [41]. Hence, designers have for a long time experimented with several design elements to increase the notion of humanness when interacting with technology. Those so-called anthropomorphic design elements are all visual, verbal and auditory characteristics that contribute to the humanlike appearance of agents [11]. As already argued, it is well established that those elements can trigger the tendency of humans to apply humanlike characteristics to nonhuman agents. Once this tendency is triggered, users are more likely to react in a way as they were interacting with another human being [16]. In other words, users are prone to apply the same social rules they learn in everyday life when interacting with an interface manifesting a high level of anthropomorphism. For instance, it was shown that already the use of simple measures such as giving names to computer agents, can increase the perception of human-likeness, which in turn leads to higher perceptions of social presence [11]. We posit that:

Hypothesis 1b: Users of interfaces with higher levels of anthropomorphism will experience higher levels of social presence.

Although both interaction type and level of anthropomorphism are expected to positively affect perceptions of social presence, prior research suggests that both these elements may be interrelated. In humancomputer-interaction literature, the concept of component consistency emerged, which refers to the perceived match between different design characteristics of a computer interface [41]. It is assumed that the consistency between these elements may influence user perceptions beyond their individual effect, since consistency lowers cognitive dissonance and increases predictability. For instance, it was found that the match in perceived humanness across different components of a computer interface positively affects information sharing [41]. Based on these findings, it may be assumed that the consistency between the design elements of an interface may increase the likelihood that the user becomes persuaded by its humanness and in turn may experience higher perceptions of social presence. Therefore, we posit that:

Hypothesis 1c: The anthropomorphizing effect (i.e., low vs. high level) will be higher for conversational than for the non-conversational interface.

According to [42], trust in a service providers' web interface may be considered as an extension of interpersonal trust. Hence, one important source of trust can be found in the design of web resources, especially when there are few "objective" clues (i.e., guarantees, reputation) to cling to. In service environments, we assume that social and emotional cues may lead to enhanced perceptions of trustworthiness when interacting with a service provider for the first time [42]. This information becomes often salient to the user in the form of peripheral cues, such as the service provider's physical appearance. As such, it was found that computer agents can increase their trustworthiness by using linguistic cues employed by humans for building interpersonal trust. In face-to-face interactions, social cues have shown to be paramount for building trust [41]. Similarly, it was found that social presence is an important antecedent for trust in IT-mediated services. Accordingly, social presence positively influences user trust in digital services environments. A socially rich experience can permit an IT artifact to exhibit a personalized touch, which may be considered an important antecedent for building trust into both the interface and the service provider. Hence, we posit that:

Hypothesis 2a: Users' perception of social presence in an interface will positively affect their trust in the interface.

Hypothesis 2b: Users' perception of social presence in an interface will positively affect their trust in the provider.

The relationship between trust and behavioral intentions has been widely discussed in different research disciplines [8]. In marketing research, it is well established that consumer trust, conceptualized as a trusting belief in a service provider, positively affects a number of behavioral intentions such as the intention to buy a service [8], to use an interface [41], or to share information [14]. The same mechanism seems to apply to trust in a IS itself. For instance, it was found that initial trust in an e-commerce recommendation agent 
can positively affect usage and buying intentions. Thus, we reexamine these relationships in this study in the context of chatbots and information sharing and posit that:

Hypothesis 3a: Users' trusting beliefs in an interface will positively affect their willingness to share information.

Hypothesis 3b: Users' trusting beliefs in an interface will positively affect their willingness to share information.

\section{Research Method}

To test our research model, we conducted an online experiment with a subsequent survey. In the following, we will discuss our sample, the experimental procedures, our experimental manipulation, our measures against common method variance, the survey instrument and our modelling methods.

\subsection{Participants}

The participants were recruited via Amazon Mechanical Turk. Each of the participants received a fixed compensation for participating in the experiment.

In total, 182 people participated in the experiment in April 2020, and we collected 160 valid data sets in total. We had to drop the data sets of participants that did not comply with the experimental procedures, e.g., failure in recognizing the experimental procedure, unusually short time to complete the survey or a large number (above $20 \%$ ) of missing survey values. The final sample consisted of 53 females, 105 males and 2 others with a mean age of 36 years. All participants were US citizens and were required to have a high school degree. Table 2 gives an overview of the demographics of the participants in each treatment condition.

Table 2. Demographics

\begin{tabular}{|c|c|c|c|c|c|c|c|}
\hline \multicolumn{2}{|c|}{$\begin{array}{l}\text { Personal } \\
\text { Information }\end{array}$} & CG & TG1 & TG2 & TG3 & Total & $\%$ \\
\hline \multicolumn{2}{|c|}{ Number of People } & 40 & 40 & 40 & 40 & 40 & \\
\hline \multirow[t]{3}{*}{ Gender } & Male & 26 & 21 & 31 & 27 & 105 & 66 \\
\hline & Female & 14 & 18 & 9 & 12 & 53 & 33 \\
\hline & Other & 0 & 1 & 0 & 1 & 2 & 1 \\
\hline \multirow{5}{*}{$\begin{array}{l}\text { Age }(\varnothing \\
36,0)\end{array}$} & $18-24$ & 2 & 2 & 0 & 6 & 10 & 6 \\
\hline & $25-34$ & 18 & 17 & 16 & 17 & 68 & 42 \\
\hline & $35-44$ & 16 & 10 & 17 & 9 & 52 & 33 \\
\hline & $45-54$ & 4 & 9 & 7 & 7 & 27 & 17 \\
\hline & $>54$ & 0 & 2 & 0 & 1 & 3 & 2 \\
\hline
\end{tabular}

\subsection{Experimental Procedures and Task}

The online experiment is based on a fully randomized 2x2 - (interaction type: chatbots vs static web survey) $x$ (anthropomorphism: low anthropomorphism vs. high anthropomorphism) between subjects' experiment design. Thus, in total we had one control group (CG) and three treatment groups (TG).

The experiment consisted of four phases: 1) randomization, 2) scenario description 3) loan application, 4) posttest. The randomization, the scenario description and posttest were identical for all four groups. Within the online experiment, the participants first received an exact description of the procedure. In this vignette [46], the participants act as customers of the Credix Bank - a fictious bank - while assuming that they are applying for a loan. Participants should visit the company website to apply for the loan. To do so, the participants went through a survey that collected (sensitive) personal information about the users living conditions and intended use of the loan. Finally, they were asked to give their personal address. The participants were able to skip questions. Each participant was randomly assigned to one of the treatment conditions. After going through the loan application process, participants were directed to the post survey.

\subsection{Design of the Experimental Manipulation}

The CG was represented by those participants that used the web interface with a low level of anthropomorphism since this configuration is traditionally used by many loan application websites. All conditions were designed to be completed by the participants using their personal computer or a smart phone.

For the manipulation of the interaction type, we used two different interfaces: a standard web survey interface and a chatbot. The web interface followed a simple survey design that allowed both for answering questions in a simple matrix format with pre-defined answer options and for responding to open questions with a simple plain text input field. The chatbot was designed based on an established framework called "Tars", which many service providers use for different customer service operation use-cases. Thus, we could rely on proven design experience for customer service chatbots as the framework has been already operationalized in several customer service scenarios. Moreover, the native designed chatbots allowed us to control for all design parameters, conveniently manipulate the interaction behavior of the chatbot, and to $\log$ the interaction behavior of the users.

For the manipulation of the level of anthropomorphism, we distinguished between two anthropomorphic design elements: 1) personification elements in the website and the humanlike appearance of the chatbot following [47] and 2) a relational 
communication style, meaning more casual and extensive communication behavior following [48]. The web interface was differentiated by personification elements using a personalized introduction and icons, which guided the participant through the loan application process (high anthropomorphism). The humanlike appearance of the chatbot was differentiated by giving the agent a name, a certain character (named) and social elements such as a longer response time (high anthropomorphism) [11]. The relational communication style incorporated more extensive and casual communication, informal question items and the use of emojis (such as those commonly used in text messaging), representing high anthropomorphism. A formal conversation tone with standardized form, proper grammar and punctuation, and formal question items was used for the low anthropomorphic versions. For both, the chatbot and the web interface, we used the same social elements, such as the same texts and questions, to ensure comparability of the effects. All experimental conditions were pre-tested to ensure manipulation. The design of the different interfaces is illustrated in Figures 2a and 2b:

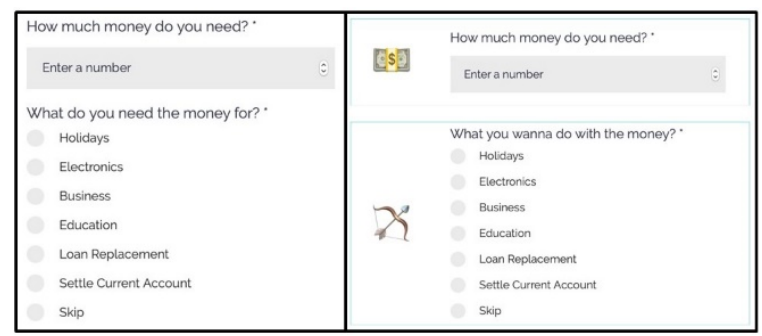

Figure 2a. Web-Survey Interfaces

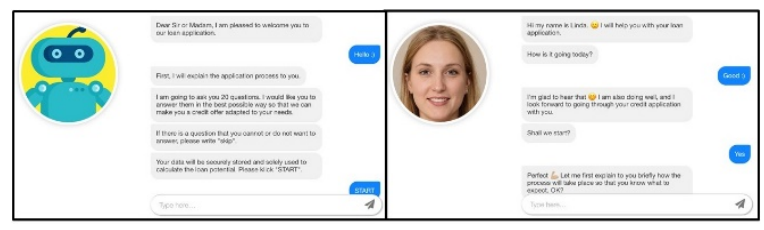

Figure 2b. Chatbot Interfaces

\subsection{Common Method Variances}

To control for common method variances that are caused by the measurement model rather than the construct measures, we applied the following procedural remedies [49]: First, we did not reveal the purpose of the experiment and provided a cover story in the vignette, to minimize bias based on psychological priming [50]. Second, we assured the participants that there were no wrong answers, asked them to provide to be as honest as possible and guaranteed anonymity, to control for effects related to social desirability [49]. Third, we conducted the Harmann`s Single Factor Test. We performed an exploratory factor analysis with all of the model indicators and examined the unrotated factor solution. Because more than one factor emerged and the first factor did not account for the majority of covariance among the measures, common method variances should not be a major problem within this study [49].

\subsection{Instrument Development}

For the operationalization of our research model, we used well established scales and adapted them to the context of chatbots in customer services. Table 3 . shows the latent constructs and the corresponding literature sources of the indicators. All latent variables were measured with reflective indicators. For this purpose, we evaluated the measurement instrument with regard to its suitability to measure the constructs in a reflective manner [51]. We used a 7-point Likert response scale that ranges from 1 ("strongly disagree) on the left side to 7 ("strongly agree") on the right side. The experimental manipulations were each coded as a binary variable.

\subsection{Modeling Methods}

To evaluate our proposed research model, we used structural equation modeling (SEM) with the variancebased partial least squares (PLS) approach [52]. PLS represents a suitable approach for this study as it provides flexibility to deal with higher-order constructs and at the same allows to deal with single item constructs such as experimental manipulations. We used SmartPLS 3.2.8 [53] as our analysis tool. Since our model includes trusting beliefs as a hierarchical latent variable, a type I reflective-reflective model was applied [51]. We followed the suggestions of [53] to use the two-stage approach instead of the repeated indicator approach. We first obtained latent variable scores (LVS) of the trusting beliefs' sub-constructs and used the LVS afterwards as reflective indicators for the mainconstruct trusting beliefs, as suggested by [42].

\section{Results}

To analyze our research model, we followed a twostep process. First, to test for reliability and validity, we analyzed the fit of our measurement models. Subsequently, we evaluated the inner model and structural relationships. 


\subsection{Measurement Models}

The evaluation of the outer model focused on the first-order constructs, the quality of which we report in Table 2:

\section{Table 3. Review on Empirical Literature on Trust in Chatbots}

\begin{tabular}{|c|c|c|c|c|}
\hline Construct & $\begin{array}{l}\text { Indicato } \\
\mathbf{r}\end{array}$ & Loading & $\begin{array}{l}\text { Composite } \\
\text { Reliability }\end{array}$ & AVE \\
\hline \multirow{10}{*}{$\begin{array}{l}\text { Trust in } \\
\text { Interface } \\
\text { (Scale adapted } \\
\text { from }[54])\end{array}$} & ICOM 1 & 0.914 & \multirow{3}{*}{0.946} & \multirow[t]{3}{*}{0.855} \\
\hline & ICOM 2 & 0.916 & & \\
\hline & ICOM 3 & 0.906 & & \\
\hline & IINT 1 & 0.928 & \multirow[t]{4}{*}{0.938} & \multirow[t]{4}{*}{0.791} \\
\hline & IINT 2 & 0.936 & & \\
\hline & IINT 3 & 0.910 & & \\
\hline & IINT 4 & 0.912 & & \\
\hline & IBEN 1 & 0.904 & \multirow[t]{3}{*}{0.937} & \multirow[t]{3}{*}{0.832} \\
\hline & IBEN 2 & 0.832 & & \\
\hline & IBEN 3 & 0.907 & & \\
\hline \multirow{9}{*}{$\begin{array}{l}\text { Trust in Service } \\
\text { Provider } \\
\text { (Scale adapted } \\
\text { from [55]) }\end{array}$} & PCOM 1 & 0.935 & \multirow[t]{3}{*}{0.955} & \multirow[t]{3}{*}{0.875} \\
\hline & PCOM 2 & 0.947 & & \\
\hline & PCOM 3 & 0.924 & & \\
\hline & PINT 1 & 0.944 & \multirow[t]{3}{*}{0.952} & \multirow[t]{3}{*}{0.868} \\
\hline & PINT 2 & 0.933 & & \\
\hline & PINT 3 & 0.918 & & \\
\hline & PBEN 1 & 0.939 & \multirow[t]{3}{*}{0.945} & \multirow[t]{3}{*}{0.852} \\
\hline & PBEN 2 & 0.911 & & \\
\hline & PBEN 3 & 0.919 & & \\
\hline \multirow{5}{*}{$\begin{array}{l}\text { Social Presence } \\
\text { (Scale adapted } \\
\text { from }[56])\end{array}$} & SP 1 & 0.945 & \multirow[t]{5}{*}{0.973} & \multirow[t]{5}{*}{0.877} \\
\hline & SP 2 & 0.914 & & \\
\hline & SP 3 & 0.934 & & \\
\hline & SP 4 & 0.954 & & \\
\hline & SP 5 & 0.935 & & \\
\hline \multirow{3}{*}{$\begin{array}{l}\text { Int. to Share } \\
\text { Information } \\
\text { (Scale adapted } \\
\text { from [55]) }\end{array}$} & INF1 & 0.884 & \multirow[t]{3}{*}{0.876} & \multirow[t]{3}{*}{0.704} \\
\hline & INF2 & 0.704 & & \\
\hline & INF3 & 0.913 & & \\
\hline
\end{tabular}

We measured indicator reliability with the standardized indicator loadings. All indicators load above the minimum value of 0.70 . Internal consistency of the latent variables was indicated by the composite reliability of all values. Values above the threshold of 0.70 show that the composite reliability is acceptable and thus substantiate the internal consistency of the latent variables. We measured convergent validity using the average variance extracted (AVE) indicating the variance of a latent construct that is explained by the related indicators.

Following, we assessed the discriminant validity with the Fornell-Larcker criterion [57]. The analysis in Table 4 shows that discriminant validity is well established. Moreover, the results of the cross-loadings indicate that all indicators load the highest on their own construct [52]. Thus, the evaluation of the measurement models shows that they fulfill the desired quality criteria.
Table 4. Discriminant Validity

\begin{tabular}{|l|l|l|l|l|l|l|l|l|l|}
\hline Construct & $\mathbf{1}$ & $\mathbf{2}$ & $\mathbf{3}$ & $\mathbf{4}$ & $\mathbf{5}$ & $\mathbf{6}$ & $\mathbf{7}$ & $\mathbf{8}$ \\
\hline 1 INF & .839 & & & & & & & \\
\hline 2 SP & .427 & .937 & & & & & & \\
\hline 3 ICOM & .488 & .659 & .912 & & & & & \\
\hline 4 IINT & .463 & .484 & .581 & .925 & & & & \\
\hline 5 IBEN & .520 & .618 & .828 & .641 & .890 & & & \\
\hline 6 PCOM & .444 & .727 & .793 & .551 & .729 & .923 & & \\
\hline 7 PINT & .510 & .564 & .661 & .640 & .656 & .766 & .935 & \\
\hline 8 PBEN & .476 & .653 & .691 & .612 & .707 & .847 & .866 & .932 \\
\hline
\end{tabular}

\subsection{Structural Model}

The analysis of the structural model incorporates path coefficients, explained variances, significance levels, effect sizes, and predictive relevance. For the model evaluation, we applied the path weighting scheme PLS algorithm with 300 iterations und set the bootstrapping procedure with 5000 samples to determine significance levels. The results for our structural model are depicted in Figure 5:

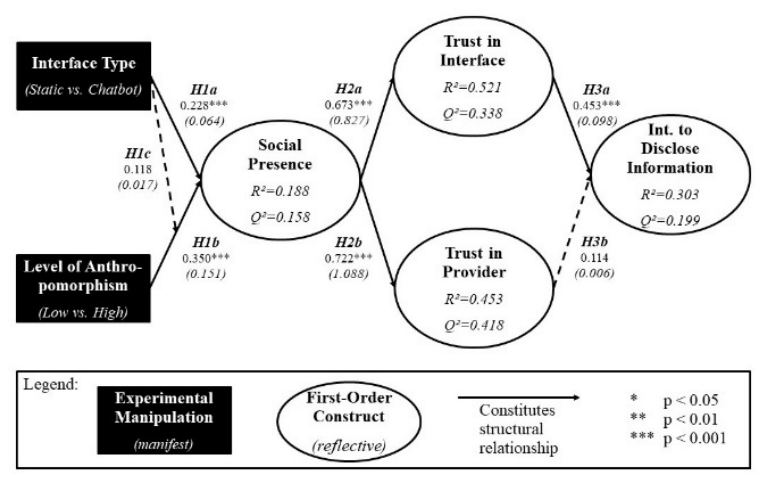

Figure 3. Results of the Structural Model

The results of the model show that both the interface modality $(\mathrm{H} 1 \mathrm{a}, \beta=0.228, \mathrm{p}=0.001)$ and the level of anthropomorphism (H1b, $\beta=0.350, p<0.001$ ) affect social presence, such that a high level of anthropomorphism and the conversational interface leads to higher perceptions of social presence. We could not find a significant moderating effect of interface modality on the path between level of anthropomorphism and social presence (H1 c, $\beta=0.118$, $\mathrm{p}=0.011)$. Social presence has a direct positive effect both on trust in the interface (H2a, $\beta=0.673, p<0.001$ ) and on trust in the provider (H2b, $\beta=0.722, p<0.001)$. Moreover, we find that trust in the interface positively affects the intention to share information (H3a, $\beta$ $=0.453, p<0.001)$. Yet, trust in the provider does not show a significant effect on the intention to share information (H3a, $\beta=0.114, p<0.001$ ).

Regarding the explained variance $\left(\mathrm{R}^{2}\right)$, the constructs social presence $\left(\mathrm{R}^{2}=0.188\right)$ and information 
disclosure intention $\left(\mathrm{R}^{2}=0.303\right)$ show a small proportion of explained variance. The two constructs trust in interface $\left(\mathrm{R}^{2}=0.453\right)$ and perceived threat $\left(\mathrm{R}^{2}=0.521\right)$ show a high proportion of explained variance.

The measurement of the prognosis relevance $Q^{2}$ determines the prognostic capability of the model. Since $\mathrm{Q}^{2}$ is above the threshold value of 0 for all endogenous reflective constructs, the predictive relevance of this structural model is given. The results show a moderate predictive relevance for the constructs trust in interface $\left(Q^{2}=0.338\right)$ and trust in service provider $\left(Q^{2}=0.418\right)$. The constructs social presence $\left(Q^{2}=0.158\right)$ and intention to share information $\left(\mathrm{Q}^{2}=0.199\right)$ show a small predictive relevance.

\section{Discussion}

This study found strong evidence for the influence of interface type and level of anthropomorphism on enhancing user trust between the interface as well as the service provider and the user. As expected, we found that conversational interfaces invoke higher social presence than non-conversational interfaces, which results in both higher trust in the interface and the service provider. We found a similar effect for the level of anthropomorphism such that higher anthropomorphism enhances user trust. All these findings support our expectations that chatbots could be effectively used for the automation of standardized service processes and, more particularly, for enhancing the user experiences in digital loan applications. Moreover, we find that trust in the interface is affecting behavioral intention (i.e., intention to share information), while trust in the service provider has no significant effect.

This study further highlights the importance of interface design in user's adoption of chatbots by creating an experience that evokes perceptions of social presence and user trust. Whereas the effect of social presence has already been explored in various contexts $[36,41]$, we extend these findings to the realm of loan applications. Moreover, to the best of our knowledge, we are the first to compare the effect of a conversational interaction logic and the increased usage of anthropomorphic design cues on user trust. Furthermore, our findings provide more empirical support for the interrelationship of social presence and user trust in automated service experience settings, while we extend these findings by showing that trust in the service provider is also enhanced.

It is noteworthy that, contrary to our expectation, that the interaction mode does not moderate the relationship between the level of anthropomorphism and user trust. This suggests that the component fit between the design elements does not play a central role in our case. This may be in line with findings on the uncanny valley phenomena, which indicate that the level of anthropomorphism of an interface only dramatically influence perceptions of social presence when reaching a certain threshold [16]. However, it may be noted that the effect may be significant for a larger data set.

Regarding its practical implications, this study showed that user trust into these standardized service processes can be enhanced by using AI-based chatbots. For service providers, already changing towards a conversational interface without applying any anthropomorphic design elements has positive effects on user trust. However, these effects become even more pronounced when using social clues. Moreover, we find indications that interface design is key to providing a trustworthy service experience, as trust in the interface has shown do be instrumental for information sharing intention in contrast to trust in the provider. Thus, this study underlines the importance of user experience design with these novel interfaces.

\section{Limitations and Future Work}

There are several limitations to this study that should be considered and underline the demand for future research. First, this study is limited to the context of loan applications, which represents a standardized and formal context. However, the effectiveness of anthropomorphic features as well as the conversational logic may depend on the context or goal. Hence, future research should take other contexts into account. Second, the participants were asked to put themselves into a situation and assume a role, which limits the external validity of our results. Although, vignettes have shown to produce reliable results, future work may reexamine the results of this study with a field experiment [46]. Finally, it should be noted that our results only capture first impressions of the users. However, the perception of social presence and in respect trust could fade away with time as users become more aware of the mechanistic nature of the IT artifact. Thus, users may show different preferences for the design elements based on their experience with the interface. Moreover, trust itself may be affected by the experience of the user, such that for instance repeated use may form trust habits. Therefore, future research should research trust in these interfaces from a longitudinal perspective.

\section{Conclusion}

The goal of our study was to better understand how AI-based chatbots and their design change users' trust and impact perceptions of the service provider, as well 
as the downstream consequences for users. To the best of our knowledge, this is the first work that contrasts the effects of traditional, non-conversational interfaces compared to now increasingly pervasive, conversational interfaces on user trust for the context of loan applications. This research contributes to the emerging field of immersive user experiences with AI-based technologies and shows that the turn-taking interaction paradigm of conversational interfaces evokes more trustworthy experiences when requesting sensitive information. Moreover, we find that trust in the interface is more important for users' behavioral intention than trust in the service provider, which underlines the critical role of these interfaces for the design of customer-facing service processes.

\section{Acknowledgements}

We thank the Swiss National Science Foundation for funding parts of this research (100013_192718).

\section{References}

[1] Dale, R.: The return of the chatbots. Nat. Lang. Eng. 22, 811-817 (2016)

[2] Følstad, A., Brandtzaeg, P.B.: Chatbots and the New World of HCI. Interactions. 24, 38-42 (2017).

[3] Adam, M., Wessel, M., Benlian, A.: AI-based chatbots in customer service and their effects on user compliance. Electron. Mark. (2020).

[4] Nordheim, C.B., Følstad, A., Bjørkli, C.A.: An Initial Model of Trust in Chatbots for Customer ServiceFindings from a Questionnaire Study. Interact. Comput. 31, 317-335 (2019)

[5] Grudin, J., Jacques, R.: Chatbots, humbots, and the quest for artificial general intelligence. In: Conference on Human Factors in Computing Systems - Proceedings. Association for Computing Machinery (2019).

[6] Griffeth, E., Simonite, T.: Facebook's Virtual Assistant M Is Dead. So Are Chatbots. (https://www.wired.com /story/facebooks-virtual-assistant-m-is-dead-so-arechatbots/), (accessed:11-22-2020) (2018).

[7] Coniam, D.: The linguistic accuracy of chatbots: Usability from an ESL perspective. Text Talk. 34, 545567 (2014)..

[8] de Bellis, E., Venkataramani Johar, G.: Autonomous Shopping Systems: Identifying and Overcoming Barriers to Consumer Adoption. J. Retail. 96, 74-87 (2020).

[9] Zierau, N., Hausch, M., Bruhin, O., Söllner, M.: Towards Developing Trust-Supporting Design Features for AIBased Chatbots in Customer Service. In: International Conference on Information Systems (ICIS). (2020).

[10] Zierau, N., Wambsganss, T., Janson, A., Schöbel, S., Leimeister, J.M.: The Anatomy of User Experience with Conversational Agents: A Taxonomy and Propositions of Service Clues. In: International Conference on Information Systems (ICIS) (2020).
[11] Feine, J., Gnewuch, U., Morana, S., Maedche, A.: A Taxonomy of Social Cues for Conversational Agents. Int. J. Hum. Comput. Stud. (2019).

[12] Kim, S., Lee, J., Gweon, G.: Comparing data from chatbot and web surveys effects of platform and conversational style on survey response quality. In: Conference on Human Factors in Computing Systems Proceedings. Association for Computing Machinery (2019).

[13] Wambsganss, T., Winkler, R., Schmid, P., Söllner, M.: Unleashing the Potential of Conversational Agents for Course Evaluations: Empirical Insights from a Comparison with Web Surveys. Twenty-Eighth Eur. Conf. Inf. Syst. 1-18 (2020).

[14] Nunamaker, J.F., Derrick, D.C., Elkins, A.C., Burgoon, J.K., Patton, M.W.: Embodied Conversational AgentBased Kiosk for Automated Interviewing. J. Manag. Inf. Syst. 28, 17-48 (2011).

[15] Bickmore, T.W., Cassell, J.: Relational Agents: A Model and Implementation of Building User Trust. In: Proceedings of the 2001 CHI Conference Human Factors in Computing Systems. pp. 396-403 (2001).

[16] Pfeuffer, N., Benlian, A., Gimpel, H., Hinz, O.: Anthropomorphic Information Systems. Bus. Inf. Syst. Eng. 61, 523-533 (2019).

[17] Knote, R., Janson, A., Söllner, M., Leimeister, J.M.: Value Co-Creation in Smart Services: A Functional Affordances Perspective on Smart Personal Assistants. J. Assoc. Inf. Syst. 2019, (2020).

[18] Følstad, A., Bae, P.: Users ' experiences with chatbots : findings from a questionnaire study. Qual. User Exp. 114 (2020).

[19] McLean, G., Osei-Frimpong, K.: Hey Alexa ... examine the variables influencing the use of artificial intelligent in-home voice assistants. Comput. Human Behav. 99, 28-37 (2019).

[20] Følstad, A., Skjuve, M., Brandtzaeg, P.: Different chatbots for different purposes: towards a typology of chatbots to understand interaction design. In: International conference on internet science proceedings. pp. 145-156 (2019).

[21] Huang, M.H., Rust, R.T.: Engaged to a Robot? The Role of AI in Service. J. Serv. Res. (2020).

[22] De Keyser, A., Köcher, S., Alkire (née Nasr), L., Verbeeck, C., Kandampully, J.: Frontline Service Technology infusion: conceptual archetypes and future research directions. J. Serv. Manag. 30, 156-183 (2019).

[23] Fuckner, M., Barthes, J.P., Scalabrin, E.E.: Using a personal assistant for exploiting service interfaces. In: Proceedings of the 2014 IEEE 18th International Conference on Computer Supported Cooperative Work in Design. pp. 89-94 (2014).

[24] Gefen, D., Larahanna, E., Straub, D.W.: Trust and TAM in Online Shopping: An Integrated Model. MIS Q. 27, 51-90 (2014).

[25] Holtgraves, T.M., Ross, S.J., Weywadt, C.R., Han, T.L.: Perceiving artificial social agents. Comput. Human Behav. 23, 2163-2174 (2007).

[26] Söllner, M., Benbasat, I., Gefen, D., Leimeister, J.M., Pavlou, P.A.: Trust. In: Bush, A. and Rai, A. (eds.) MIS Quaterly Research Curations (2016). 
[27] Zierau, N., Engel, C., Söllner, M., Leimeister, J.M.: Trust in Smart Personal Assistants: A Systematic Literature Review and Development of a Research Agenda. In: WI2020 Zentrale Tracks. pp. 99-114 (2020).

[28] Maedche, A., Legner, C., Benlian, A., Berger, B., Gimpel, H., Hess, T., Hinz, O., Morana, S., Söllner, M.: AI-Based Digital Assistants. Bus. Inf. Syst. Eng. (2019).

[29] Clark, L., Munteanu, C., Wade, V., Cowan, B.R., Pantidi, N., Cooney, O., Doyle, P., Garaialde, D., Edwards, J., Spillane, B., Gilmartin, E., Murad, C.: What Makes a Good Conversation? In: Proceedings of the 2019 CHI Conference Human Factors in Computing Systems (2019).

[30] Rai, A.: Avoiding type III errors: Formulating is research problems that matter. MIS Q. Manag. Inf. Syst. 41, iii-vii (2017).

[31] Söllner, M., Hoffmann, A., Leimeister, J.M.: Why different trust relationships matter for information systems users. Eur. J. Inf. Syst. 25, 274-287 (2016).

[32] Lee, J.D., See, K.A.: Trust in Automation: Designing for Appropriate Reliance. Hum. Factors. 46, 50-80 (2004).

[33] Söllner, M., Pavlou, P.A., Leimeister, J.M.: Understanding the Development of Trust: Comparing Trust in the IT Artifact and Trust in the Provider. In: Academy of Management Annual Meeting 2016, Anaheim, CA, USA (2016).

[34] Mayer, R.C., Davis, J.H., Schoorman, D.F.: An Integrative Model of Organizational Trust. Acad. Manag. Rev. 20, 709-734 (1995).

[35] Pfeuffer, N., Adam, M., Toutaoui, J., Hinz, O., Benlian, A.: Mr. and Mrs. Conversational Agent - Gender Stereotyping in Judge-Advisor Systems and the Role of Egocentric Bias. ICIS 2019 Proc. (2019).

[36] Wang, W., Qiu, L., Kim, D., Benbasat, I.: Effects of rational and social appeals of online recommendation agents on cognition- and affect-based trust. Decis. Support Syst. 86, 48-60 (2016).

[37] Shamekhi, A., Czerwinski, M., Mark, G., Novotny, M., Bennett, G.A.: An Exploratory Study Toward the Preferred Conversational Style for Compatible Virtual Agents. In: International Conference on Intelligent Virtual Agents (2016).

[38] Bickmore, T., Mauer, D.: Modalities for building relationships with handheld computer agents. In: Conference on Human Factors in Computing Systems Proceedings. pp. 544-549 (2006).

[39] Yu, Q., Nguyen, T., Prakkamakul, S., Salehi, N.: "I Almost Fell in Love with a Machine": Speaking with Computers Affects Self-disclosure. In: Extended Abstracts of the 2019 CHI Conference on Human Factors in Computing Systems. pp. 1-6 (2019).

[40] Schroeder, J., Schroeder, M.: Trusting in Machines: How Mode of Interaction Affects Willingness to Share Personal Information with Machines. In: Proceedings of the 51st Hawaii International Conference on System Sciences (2018).

[41] Qiu, L., Benbasat, I.: Evaluating Anthropomorphic Product Recommendation Agents: A Social Relationship Perspective to Designing Information Systems. J. Manag. Inf. Syst. 25, 145-182 (2009).
[42] Wang, W., Benbasat, I.: Trust in and Adoption of Online Recommendation. J. Assoc. Inf. Syst. 6, 72-101 (2005).

[43] Nass, C., Moon, Y.: Machines and mindlessness: Social responses to computers. J. Soc. Issues. 56, 81-103 (2000).

[44] Nass, C., Steuer, J., Tauber, E.R.: Computer are social actors. In: Conference on Human Factors in Computing Systems - Proceedings. pp. $72-78$ (1994).

[45] Schuetzler, R.M., Grimes, M., Scott Giboney, J., Buckman, J., Scott, J.: Facilitating Natural Conversational Agent Interactions: Lessons from a Deception Experiment. (2014).

[46] Aguinis, H., Bradley, K.J.: Best Practice Recommendations for Designing and Implementing Experimental Vignette Methodology Studies. Organ. Res. Methods. 17, 351-371 (2014).

[47] Araujo, T.: Living up to the chatbot hype: The influence of anthropomorphic design cues and communicative agency framing on conversational agent and company perceptions. Comput. Human Behav. 85, 183-189 (2018).

[48] Bickmore, T.W., Caruso, L., Clough-Gorr, K., Heeren, T.: "It's just like you talk to a friend" relational agents for older adults. Interact. Comput. 17, 711-735 (2005).

[49] Podsakoff, P.M., MacKenzie, S.B., Lee, J.Y., Podsakoff, N.P.: Common Method Biases in Behavioral Research: A Critical Review of the Literature and Recommended Remedies. J. Appl. Psychol. 88, 879903 (2003).

[50] Paulhus, D.L., Harms, P.D., Bruce, M.N., Lysy, D.C.: The Over-Claiming Technique: Measuring SelfEnhancement Independent of Ability. J. Pers. Soc. Psychol. 84, 890-904 (2003).

[51] Jarvis, C.B., MacKenzie, S.B., Podsakoff, P.M.: A Critical Review of Construct Indicators and Measurement Model Misspecification in Marketing and Consumer Research. J. Consum. Res. 30, 199-218 (2003).

[52] Chin, W.W.: Commentary Issues and Opinion on Structural Equation Modeling Clear Reporting. Mod. methods Bus. Res. Methodol. Bus. Manag. 22, vii-xvi (1998).

[53] Ringle, C.M., Sarstedt, M., Straub, D.W.: A critical look at the use of PLS-SEM in MIS quarterly. MIS Q. Manag. Inf. Syst. 36, (2012).

[54] McKnight, D.H., Choudhury, V., Kacmar, C.: Developing and validating trust measures for ecommerce: An integrative typology. Inf. Syst. Res. 13, 334-359 (2002).

[55] Harrison McKnight, D., Choudhury, V., Kacmar, C.: The impact of initial consumer trust on intentions to transact with a web site: A trust building model. J. Strateg. Inf. Syst. 11, 297-323 (2002).

[56] Gefen, D., Straub, D.: Managing User Trust in B2C eServices. e-Service J. 2, 7 (2003).

[57] Fornell, C., Larcker, D.F.: Evaluating Structural Equation Models with Unobservable Variables and Measurement Error. J. Mark. Res. 18, 39 (1981). 